\title{
O vácuo no contexto das representações sociais: uma hipótese explicativa para a representação social da loucura
}

\author{
João Fernando Rech Wachelke \\ Universidade Federal de Santa Catarina
}

\begin{abstract}
Resumo
O presente artigo sugere que os conteúdos culturais podem ser estudados com o auxílio da teoria das representações sociais. São mencionados os resultados de alguns estudos que descreveram a representação social da loucura, enfatizando-se uma característica recorrente: a alteridade, ou seja, a loucura é um objeto cercado de insegurança e ambigüidade, representado como algo distante de quem o representa. Alguns autores argumentam que isso pode ser decorrência de uma falha estrutural da representação social da loucura. É proposta uma hipótese para explicar esse fenômeno a partir de um conflito entre sistemas de representações científicas e culturais, o que originaria um problema de cobertura da loucura enquanto objeto a que é dado o nome de vácuo representacional. São apontadas limitações da hipótese levantada e ressalta-se a necessidade de condução de estudos para verificar sua adequação e generalidade.
\end{abstract}

Palavras-chave: representações sociais; loucura; representações culturais; representações científicas

\begin{abstract}
The vacuum in the context of social representations: an explanatory hypothesis for the social representation of madness. The present article suggests that cultural contents can be studied with the help of social representations theory. The results of some studies that have described the social representation of madness are described, emphasizing a recurrent characteristic: otherness, that is, madness is an object surrounded by insecurity and ambiguity, represented as something distant from those who represent it. Some authors say that it might be due to a structural flaw in the social representation of madness. A hypothesis to explain this phenomenon from a conflict between systems of scientific and cultural representations is proposed; such a conflict would cause a coverage problem concerning madness as an object, to which the name of representational is given. Limitations of the hypothesis are pointed out, and the need to carry out studies to verify its adequacy and generalizability is stressed.
\end{abstract}

Keywords: social representations; madness; cultural representations; scientific representations

A cultura é considerada por alguns autores como a principal característica humana (Laraia, 1997), em certa medida a característica que possibilita ao homem diferenciar-se de outras espécies. Ao se adotar uma definição de cultura como "o complexo dos padrões de comportamento, das crenças, das instituições e de outros valores espirituais e materiais transmitidos coletivamente e característicos de uma sociedade” (Ferreira, 1975, p. 409), é feita referência a conteúdos cognitivos e afetivos compartilhados socialmente por meio dos quais membros de um dado grupo social dão conta da realidade em que estão inseridos, e nos quais embasam suas práticas na vida cotidiana.

Os conteúdos culturais, expressos por meio de representações, constituem o objeto de estudo de várias ciências sociais, principalmente da antropologia (Sperber, 2001), que toma a cultura como sua principal preocupação. Nas últimas déca- das, contudo, uma perspectiva teórica psicossociológica originada da França tem crescido em popularidade ao fornecer uma maneira de compreender a cognição social e suas decorrências com ênfase no substrato dos grupos e sociedades, em oposição a uma psicologia social norte-americana restrita, sobretudo, ao estudo das relações interindividuais. Trata-se de uma forma sociológica da psicologia social (Farr, 2002), cujo "carro-chefe" é a teoria das representações sociais de Serge Moscovici.

Para Moscovici (2003), representações sociais é uma forma de conhecimento que equivale ao senso comum dos grupos sociais. O autor diferencia dois mundos cognitivos opostos, característicos da modernidade contemporânea: um universo reificado de regularidades e invariâncias, em que se destaca o pensamento científico; e um universo consensual, em que os indivíduos podem ser considerados pensadores 
amadores, um mundo em que não há uma verdade como na ciência, mas sim versões compartilhadas por grupos: um mundo em que as pessoas tentam lidar com os objetos da realidade por meio da conversação e negociação constantes. As representações sociais correspondem à forma de conhecimento desse segundo universo.

Mais do que meras mediadoras entre estímulo e resposta, as representações, para Moscovici (2003), são variáveis independentes que determinam tanto as características do estímulo quando da resposta comportamental. Tal é a importância atribuída a esse fenômeno, que Moscovici (1985) reorienta a psicologia social em função dele, definindo a ideologia (a saber, as representações e cognições sociais) e os processos da comunicação como os objetos de estudo da psicologia social. Para o autor, a tarefa principal da psicologia social é estudar as representações no que se referem às suas origens, características e desenvolvimento.

As representações sociais, enquanto forma de conhecimento, têm um propósito claro: tornar familiares os objetos sociais não-familiares, ou seja, "aproximar” cognitivamente dos atores sociais aquilo que lhes é estranho. Isso é feito por meio de dois processos, ancoragem (processo por meio do qual que novos objetos são classificados e alinhados com conhecimento já existente) e objetivação (materialização de um conceito; de certo modo, reprodução de uma idéia abstrata em imagem). Nesse sentido, um novo fato social, tal como a emergência de alguma nova teoria científica, é primeiramente ancorado, situado juntamente às idéias já existentes do grupo, e posteriormente o abstrato torna-se concreto, na forma de alguma metáfora ou imagem, em que consiste a objetivação.

A palavra social, que acompanha o termo representação, possui importância fundamental para a teoria das representações sociais. As representações sociais não são explicadas pelos mecanismos cognitivos individuais, mas sim pelas características do grupo. Moscovici resgatou a noção das representações sociais da sociologia de Durkheim, que as denominava representações coletivas; as representações sociais de Moscovici, contudo, diferem em alguns aspectos das durhkeimianas. Embora Moscovici tenha afirmado que as noções de representações coletivas e sociais sejam difíceis de distinguir (Moscovici \& Marková, 2003), de modo geral se admite uma diferença no que tange à estabilidade, atualidade e especificidade das segundas em relação às primeiras. Enquanto as representações coletivas apresentam-se estáveis (quase estáticas) e caracterizam principalmente sociedades primitivas, referindo-se a grupos amplos, considera-se que as representações sociais é o senso comum dos Séculos XX e XXI, período marcado pelo desenvolvimento dos meios de comunicação de massa. Assim, as representações sociais são passíveis de mudança, exibindo uma dimensão dinâmica. Já no que tange à questão de especificidade, o conceito durkheimiano de representação é um tanto geral, abrangendo quaisquer idéias, instituições ou crenças ocorrentes em alguma comunidade. Moscovici reserva o nome de representação social ao conhecimento que familiariza o novo e incomum para um grupo ou categoria determinado, instrumentalizandoo a agir na realidade social (Moscovici, 1981; 2003). A definição de representações sociais de Denise Jodelet (2001) é sintética e abarca os elementos essenciais desse fenômeno. Assim, a representação social "é uma forma de conhecimento, socialmente elaborada e partilhada, com um objetivo prático, e que contribui para a construção de uma realidade comum a um conjunto social” (p. 22).

Ao lidar com a cognição social na forma de representações, a psicologia social abre as portas da interdisciplinaridade e possibilita um diálogo com as demais ciências sociais, em especial a antropologia, no que tange à questão da cultura. As representações sociais, na medida em que expressam o conhecimento de grupos, viabilizam o estudo da cultura enquanto regente da vida social. A teoria das representações sociais tem se mostrado uma ferramenta poderosa na compreensão do conhecimento humano acerca de uma variedade significativa de fenômenos. Outra de suas vantagens reside em sua abertura a uma multiplicidade de técnicas de observação (Wagner, Duven, Farr \& Verma, 1999a; NascimentoSchulze \& Camargo, 2000), o que garante às descobertas na área uma visão abrangente decorrente de múltiplos enfoques sobre os problemas estudados.

Sperber (2001) visualiza um diálogo entre o estudo das representações e o estudo antropológico da cultura. Para o autor, representações pertencentes a um grupo social e que sejam simultaneamente dotadas de grande durabilidade são representações culturais. O próprio Moscovici (1987), ao se referir à perspectiva das representações sociais, falou em uma "antropologia da cultura moderna".

Portanto, representações culturais podem ser consideradas representações sociais, contanto que apresentem algumas peculiaridades: (1) serem representações duradouras, antigas, pelo menos no que se refere a suas características distintivas; (2) possuírem alta estabilidade e resistência à mudança, em comparação com as demais representações; e (3) possuírem certa especificidade no que diz respeito aos grupos que compartilham e detêm essas representações, geralmente no sentido de uma coletividade mais ampla como uma tribo, nação ou comunidade.

Retomando o conceito de cultura enquanto código simbólico, mencionado anteriormente, esta poderia também ser entendida, sob uma perspectiva psicossocial, como um sistema coerente de representações sociais estáveis e duradouras, compartilhadas por um grupo social e transmitidas coletivamente. Nesse sentido, em certas circunstâncias, a teoria das representações sociais possibilitaria investigações de conteúdos culturais. Contudo, é relevante notar que há autores que aparentam discordar dessa definição, negando às representações sociais o estatuto de representações culturais, e aproximando as últimas das representações coletivas de Durkheim (Wagner \& col, 1999a).

Wagner (1998) afirma que as representações culturais são hegemônicas em grandes coletividades, não possuindo laços com grupos específicos. Enraizadas no pensamento e comportamento dos povos, as representações desse tipo são 
adquiridas e desenvolvidas cedo na vida das pessoas. Contudo, Wagner admite que o imaginário cultural pode constituir objetos de representações sociais; nesse caso, tratar-seia de conhecimento adquirido mais recentemente que o conhecimento cultural, e situado no contexto de grupos específicos. De todo modo, optamos por tratar as representações culturais enquanto uma classe diferente de representações sociais. Mesmo a distinção realizada por Wagner e seus colaboradores (1999b), a nosso ver, não inviabiliza uma análise de representações culturais como representações sociais, uma vez que sejam respeitadas suas propriedades características, como mencionadas pelo autor e enumeradas acima. É essa perspectiva que adotaremos durante esta argumentação.

Tendo introduzido a teoria das representações sociais no contexto da cultura, prosseguiremos discutindo as descobertas provenientes de investigações sobre um dos mais tradicionais temas de pesquisa dessa perspectiva psicossociológica: a loucura. A representação social da loucura possui uma peculiaridade em relação às demais representações sociais existentes: uma característica que aparece presente com freqüência associada à loucura ou doença mental é um forte estranhamento, o que vem de certa forma de encontro à função principal das representações sociais de acordo com Moscovici: tornar familiar aquilo que é insólito. Após uma breve revisão bibliográfica sobre os achados na área, analisaremos com maior profundidade esse fenômeno, propondo em caráter de hipótese um modelo explicativo para dar conta dele, ou pelo menos de suscitar novas reflexões sobre essa problemática.

\section{A representação social da loucura}

De importância fundamental para o estudo da representação social da loucura é a obra de Denise Jodelet, publicada em 1989, intitulada Folies et réprésentations sociales, originada de sua tese de doutorado. Na pesquisa apresentada, atualmente já disponível em português (Jodelet, 2005), a autora entrevistou habitantes de uma comunidade em que doentes mentais viviam como pensionistas, junto a famílias locais. Após uma análise aprofundada do conteúdo implícito em entrevistas, a autora identificou práticas de discriminação por parte dos moradores do vilarejo em relação aos pacientes. Os moradores, considerando seus hóspedes estranhos, imprevisíveis e diferentes, excluíam-nos sutilmente, marginalizando-os. Uma representação social que tomava o louco como uma ameaça era responsável por um distanciamento entre os habitantes da vila e os doentes. Estes eram tratados por aqueles como outros, separados do grupo de referência dos moradores do vilarejo (Jodelet, 2001; Morant, 1995; Wagner et al., 1999b). Desde então, os estudos sobre a representação social da loucura e da doença mental têm freqüentemente apontado para a dimensão da alteridade (otherness) e da diferença (Morant $\&$ Rose, 2002).

Wagner e colaboradores (1999b) estudaram a representação social da loucura na cidade hindu de Patna. A loucura é aí caracterizada de forma negativa e ameaçadora, como um estado que exige tratamento especializado; por outro lado, é feita uma distinção com relação a estados menores de doença mental, que poderiam ser tratados dentro do seio familiar sem a necessidade de intervenção específica. Os sujeitos de Wagner e colaboradores representam a loucura por meio de um referencial misto formado, em parte, por noções psiquiátricas que estavam começando a penetrar na sociedade hindu, e em parte por conhecimento tradicional sobre causas da doença mental e formas de tratamento por curandeirismo. Os autores verificaram que seus sujeitos indicaram problemas da vida cotidiana, tais como casamentos infelizes, violência conjugal e paixão sexual reprimida, como contextos de que se originam a loucura e a doença mental, na medida em que há tensão entre desejos e normas sociais proibitivas. A família também é considerada uma instituição de suprema importância, e em alguns casos a doença mental é vista como uma falta de ajustamento ao meio familiar. O grupo da família poderia solucionar alguns casos de aflições mentais; caso isso não fosse possível, entraria em cena o psiquiatra.

Os dados de Wagner e colaboradores (1999b) são exemplos da complexidade que podem caracterizar as interações entre sistemas de representações sociais, no caso a entrada de concepções ocidentais num ideário tradicional, em alguns momentos gerando representações contraditórias, em outros uma espécie de sincretismo cultural harmônico. É exatamente em cenários de mudança e inovação como esse que a dinamicidade das representações sociais pode ser mais bem observada.

Um cenário semelhante foi descrito por Moscovici (1978) na obra com que inaugurou o domínio das representações sociais. Na França da década de 50, a psicanálise era novidade, e o conhecimento psicanalítico forneceu à população novas estruturas para nomear a loucura. O que antes era distante e considerado característica do "outro" passou a ser de domínio comum, por meio de conceitos como a neurose e os complexos. Quebrando uma relação de separação completa entre a patologia e a normalidade psíquicas, a psicanálise aproximou ambas, estabelecendo continuidade entre saúde e doença mental.

Numa das pesquisas relatadas por Wagner et al. (1999a), Rose, investigando a representação social da loucura na televisão britânica, por meio de uma análise de conteúdo, deparou-se com uma representação da pessoa mentalmente doente repleta de instabilidade e multiplicidade semântica, e caracterizada, sobretudo, pela alteridade. O louco é visto como uma pessoa imprevisível, associada à violência e ao perigo.

Também Morant (1995), ao investigar a representação da doença mental junto a profissionais de saúde franceses e ingleses, encontrou a incerteza e a multiplicidade como características centrais. As representações desse grupo mostram-se repletas de contradição: em alguns casos a loucura é explicada com base em um paradigma médico, expresso por meio de termos psiquiátricos; noutras ocasiões, a doença mental é explicada por meio de um modelo funcional, privilegiando a adaptação ao meio.

A alteridade está presente na representação pertencente a esses profissionais, mas não é generalizada a todos os ti- 
pos de doença mental. A diferença é parte integrante principalmente da representação das psicoses; as neuroses são entendidas como um exagero da experiência normal, e, portanto, a distância entre o quadro neurótico e a esfera psicossocial do representador é menor, o que caracteriza uma mesmidade (sameness). Essa peculiaridade parece estar presente também no estudo de Foster (2001), que sugere que há distinção entre as representações de diversos tipos de doença mental, com base num processo de categorização de casos individuais de acordo com contínuos de diferenciação. Portanto, o grau de uma doença mental poderia ser avaliado por ela requerer ou não tratamento, pela quantidade de tempo em que os sintomas podem ser observados; pelo período de duração da doença e pelo dano potencial que a doença pode trazer para a sociedade e para o próprio doente. Nesse sentido, distúrbios percebidos como mais suaves ou brandos não inspiram sentimento de alteridade tão forte quanto quadros esquizofrênicos ou autistas. Por outro lado, a autora lembra que a mera possibilidade de associar essas formas menos graves de enfermidades ao rótulo mais abrangente de "doença mental” pode ser responsável em certa medida por uma vinculação com a imagem de alienação que acompanha a loucura de forma geral.

Krause (2002), por sua vez, estudou a representação social sobre problemas psicológicos de uma população chilena de baixo nível sócio-econômico. Seus dados indicam a presença marcante da loucura como um conteúdo associado aos problemas psicológicos. Para a maior parte dos sujeitos pesquisados, o profissional de psicologia deveria atuar com pessoas “loucas”.

O estudo de Krause (2002) também permitiu a identificação de elementos da representação social dos problemas psicológicos mais próximos da vida cotidiana, menos enraizados e possivelmente menos centrais que a associação com a loucura e patologia. Essa variedade de significados também foi encontrada nos meios de comunicação em massa do Chile, que por sua vez foram influenciados por estudos epidemiológicos. Encontra-se aí um exemplo do trajeto que percorre o conhecimento originado do meio científico restrito até chegar ao senso comum (representações sociais) através da mídia.

Morant e Rose (2002), apercebendo-se das regularidades referentes à representação social da loucura em grande parte dos estudos da área, apontam para o fato de que a loucura parece constituir um desafio para a teoria das representações sociais. Se as representações sociais têm como finalidade tornar familiar aquilo que não é, a loucura parece ser uma notável exceção à regra, uma vez que a atribuição da dimensão da alteridade está quase sempre presente em maior ou menor grau, acompanhada por uma grande variedade de significados, forte ambivalência e insegurança. Os autores oferecem duas interpretações possíveis para essa problemática.

A primeira delas trata o não-familiar como um conteúdo representacional, de forma que classificar um dado objeto social, no caso a loucura, como não-familiar, é lidar com ele de forma eficaz, familiarizando-o. Afastar o que é estranho, assim preservando a própria identidade social, é recurso empregado em grande variedade de contextos sociais, conforme mencionado pelos autores. Os ocidentais freqüentemente associam a condição de doença com o outro, projetando o que é simbolizado como mau longe do espaço do in-group (Crawford, 1994). Pode-se dizer que o que se observa é de certa forma uma tensão semelhante a um desequilíbrio na representação, em nível da consonância do pensamento grupal. A idéia do louco enquanto semelhante é ameaçadora, e, portanto, o louco é excluído, considerado fundamentalmente diferente do grupo que representa no que consiste essencialmente a propriedade da alteridade. Nesses termos, faz-se referência a um processo que lembraria o estado de dissonância cognitiva (Festinger, 1957) levando em consideração, entretanto, que este é estudado no contexto das atitudes individuais, e que o desequilíbrio que mencionamos estaria vinculado de modo mais geral a representações compartilhadas.

Outra possibilidade interpretativa sugerida por Morant e Rose (op.cit) implica a natureza estrutural da não-familiaridade da loucura. Uma multiplicidade de significados e um estado de confusão desses significados, consistindo numa ausência de âncoras, tornariam a representação instável e impediria a classificação da doença mental, fazendo da loucura um objeto social sui generis.

É de nossa compreensão que os dois modelos fornecidos pelos autores não são necessariamente incompatíveis; ambos podem ser adequados para explicar dois aspectos diferentes de um mesmo processo. Uma interpretação viável do que ocorre com a representação social da loucura consiste em considerar o fenômeno em meio ao contexto das possibilidades explicativas fornecidas por duas grandes formas de conhecimento, a saber, a cultura e a ciência, entendidas aqui como dois grandes sistemas de representações sociais.

\section{A falha estrutural}

O que propomos é considerar que nenhum dos dois sistemas representacionais (ciência e tradição cultural) oferece possibilidade de explicar satisfatoriamente a loucura, enquanto objeto da sociedade. As representações culturais encarregaram-se historicamente de lidar com a loucura de forma relativamente eficaz. Para o homem primitivo e o homem medieval, por exemplo, a loucura poderia ser explicada em termos familiares por meio de teorias demonológicas, atribuindo a espíritos ou forças malignas a causa da condição de insanidade (Abuchaem, 1981). No entanto, a emergência do pensamento científico e sua ascensão na hierarquia dos tipos de conhecimento reservaram às culturas tradicionais estatuto inferior ao da ciência, que zela pela observação e pelo empirismo como princípios para nortear o conhecimento, entre outros.

Decorrência dessa configuração de forças entre as formas de conhecer é a rejeição das explicações culturais para dar conta de fenômenos de que se ocupam presentemente os cientistas. A loucura, objeto de estudo tanto da psicologia 
quanto da psiquiatria, insere-se nesse contexto. No entanto, ao mesmo tempo em que repudia as teorias do senso comum sobre a loucura, a ciência não fornece boas explicações para familiarizar o fenômeno. Mesmo para os cientistas, as doenças mentais mais graves ainda permanecem permeadas pela obscuridade e incerteza.

Fato que corrobora essa constatação é o grande desconhecimento que ainda existe acerca das ligações das doenças mentais com o ambiente e com a genética, ou a ausência de algo que se aproxime de um consenso sobre as formas de tratamento adequadas para casos patológicos mais graves, como as psicoses (o que se reflete na existência de grande diversidade de escolas psicológicas e psiquiátricas direcionadas para a saúde mental, muitas vezes antagônicas), ou mesmo a não-obtenção de resultados expressivos no que diz respeito à melhora na qualidade de vida dos pacientes. Apesar de um notável progresso realizado pela psiquiatria e pela psicologia, as evidências sugerem que a ciência não domina com segurança a loucura. Eis que se estabelece uma situação em que nem ciência nem cultura possuem uma explicação confiável para o fenômeno da doença mental, o que garante sua especificidade enquanto objeto social e provoca seu afastamento e a emergência de um sentimento de alteridade por parte de quem a representa.

É de se esperar que uma vez que a ciência ofereça melhores recursos explicativos, essa distância diminua. Isso já foi observado em alguma medida com o surgimento da psicanálise (Moscovici, 1978), que aproximou normal e patológico e mobilizou toda uma série de classificações para condições antes nomeadas loucura ou anormalidade, pura e simplesmente. Esse aspecto dinâmico está também presente no menor distanciamento existente na representação da neurose, tida como um distúrbio da vida cotidiana, em oposição à psicose, ainda largamente incompreendida e mais semelhante, devido a isso, ao que se chama de loucura.

Portanto, a dinâmica subjacente à representação social da loucura, conforme os modelos propostos por Morant e Rose (2002), pode ser caracterizada pela seguinte seqüência de eventos: (1) uma ausência de conhecimento adequado, tanto cultural quanto científico, impede a ancoragem adequada da loucura; (2) a loucura é então representada como um objeto instável, não-familiar, inspirador de ansiedade e ameaçador da ordem social devido à sua incompreensão; e (3) a impossibilidade de tornar a loucura um objeto social familiar faz com que os grupos a rejeitem, afastando-a e conferindo a ela o caráter de "outra”.

É relevante notar que esse encadeamento de fatos pode ser minimizado em situações em que as representações científicas e culturais não sejam consideradas mutuamente excludentes. O estudo de Wagner et al. (1999b) apresenta sujeitos que representam a doença mental de forma mista, entrelaçando noções da ciência e da tradição. Mas mesmo nesse contexto o sistema de representações da ciência parece possuir estatuto superior na mentalidade dos sujeitos hindus, como expressam os autores:
É essa idéia do progresso como a superação da tradição que provê um contexto para a emergência da representação social da loucura, dentro da qual uma visão de loucura associada aos feitos científicos da profissão psiquiátrica pode também se dizer progressiva, marcada por sua modernidade em contraste com as representações tradicionais da loucura como formas de possessão de espíritos (Wagner et al., 1999b, p. 440).

É possível supor, a partir dos dados apresentados pelos autores, que mesmo a sociedade hindu, que apresenta uma representação mista da loucura, no que se refere aos sistemas representacionais de que suas imagens se "alimentam", esteja passando por uma mudança cultural que poderá, inclusive, dar origem ao mesmo vácuo representacional observado nos estudos de Morant, Rose e Jodelet já referidos, e tantas outras pesquisas sobre o conhecimento social de que os grupos se utilizam para caracterizar a loucura.

\section{O vácuo representacional}

Dessas considerações sobre a representação da loucura é possível derivar bases para uma hipótese contextualizada na teoria das representações sociais capaz de dar lugar também à não-familiaridade, pelo menos no presente caso. A possibilidade dessa hipótese, que assume a forma de um modelo, está fortemente relacionada à noção de sistemas representacionais, a que nos referimos há pouco; torna-se necessário, para que possa ser alcançada maior clareza na explanação, voltar a esse conceito e aprofundar-se por um momento nesse tópico.

$\mathrm{Na}$ medida em que as representações sociais assemelham-se no que diz respeito a seu conteúdo e estrutura, elas podem ser consideradas em conjunto; uma vez que esse conjunto seja coeso e seja possível identificar regularidades nas diversas representações que justifiquem seu agrupamento, elas estarão formando o que chamaremos de um sistema representacional. Dito de outra forma considera-se um sistema representacional uma representação social mais abrangente sobre alguma forma de conhecer a realidade, que forneça princípios básicos para a criação e modificação de outras representações sociais. Assim, poder-se-ia citar como exemplos desses sistemas representacionais o sistema de representações relacionadas à ciência (enquanto método de produção de conhecimento pautado pela observação e a que estão associadas às representações científicas derivadas de seu emprego), e os diversos sistemas culturais (enquanto conjuntos coerentes de representações sociais de caráter cultural, conforme já discutido anteriormente).

Há que se diferenciar os sistemas representacionais da noção mais ampla de forma de conhecimento. O sistema representacional da ciência não é a ciência propriamente dita, mas sim um conjunto de representações sociais (ou seja, um conhecimento compartilhado e situado na esfera do senso comum) que têm em comum o fato de ancorar-se em noções científicas. Desde a Idade Moderna, com o surgimento do positivismo e da ciência, as representações sociais baseadas na ciência tendem a ter primazia nas sociedades ocidentais que têm acesso a essa forma de conhecimento. Por outro 
lado, um sistema representacional cultural não deve ser confundido com o conceito de cultura sem ser contextualizado. Cada cultura específica, ou melhor, cada conjunto de crenças culturais, pode ser tratado como um sistema representacional do tipo cultural na medida em que faz sentido por si só para uma dada coletividade. Além disso, não está descartada a possibilidade de que um sistema representacional possa implicar uma quantidade de sub-sistemas de representações, muitas vezes incompatíveis entre si. Exemplo disso é a própria psicologia, um nome genérico para uma ciência que abarca visões de homem que podem até mesmo ser contraditórias, como o comportamentalismo e a psicanálise.

Embora a noção de sistema representacional possa parecer estranha a alguns, não a vemos como algo novo à teoria das representações sociais; trata-se basicamente de um elemento taxonômico introduzido para tornar mais clara uma análise macroestrutural. É pertinente ressaltar que se trata de uma noção sem limites bem definidos, proposta devido à conveniência de sua utilização na presente argumentação. Imagina-se que seria possível, por exemplo, em vez de empregar a noção de sistemas, chamar a essas representações de representações que regulam outras representações, matrizes representacionais ou algum nome semelhante. Optamos pela expressão sistemas representacionais devido à economia proporcionada no decorrer da explanação, e por julgar que essa denominação, ainda que um tanto imprecisa, permita o entendimento da hipótese delineada.

$\mathrm{O}$ conceito de sistemas representacionais justifica-se pelo dinamismo crescente que vem caracterizando as representações sociais desde o surgimento da ciência. Por muito tempo o conhecimento de que as coletividades humanas se utilizavam para entender a realidade tinha base essencialmente cultural, e, portanto, dotada de relativa estabilidade e durabilidade. No entanto, com a emergência do sistema representacional científico, observa-se um conflito entre dois sistemas de representação, duas formas de compreender e explicar as coisas. As representações sociais originadas da ciência gradualmente negam e substituem o conhecimento cultural fortemente arraigado nas práticas e crenças dos diversos povos. E assim faz-se relevante observar as relações entre esses dois grandes sistemas de representações, que no caso de objetos sociais como a loucura, mostram-se fortemente incompatíveis.

Um objeto social não existe no vazio. Portanto, todo objeto social está associado a uma representação (ou pelo menos dá origem a alguns elementos de uma representação, tais como atitudes), que por sua vez pode se inserir no contexto mais amplo de um sistema representacional. Isso se dá porque as representações sociais é um tipo de conhecimento que instrumentaliza os grupos a agirem sobre a realidade social, possibilitando um diagnóstico, uma compreensão dos objetos desse meio. Todavia, os estudos aqui citados levantam a hipótese de que muitas vezes essa compreensão pode não ser completamente bem sucedida. Conforme Morant e Rose (2002) sugerem, há margem para que se pense a existência de algum problema estrutural na representação social da loucura no que diz respeito a sua ancoragem, o que tornaria a representação instável.

A loucura foi, por muito tempo, explicada por representações ligadas aos sistemas culturais de cada comunidade. Demônios, maldições, espíritos, profecias e coisas do gênero foram freqüentemente evocados na tentativa de entender esse tipo de comportamento desviante no decorrer da história, conforme descrito por Abuchaem (1981). Como essas explicações estavam ancoradas juntamente às outras representações culturais desses grupos, podia ser observada uma cerca coerência, uma compatibilidade entre as representações da loucura e as demais representações sobre a realidade social. Essa relação entre sistema representacional e objeto está representada na parte I da Figura 1: o sistema representacional é simbolizado como uma elipse, que engloba totalmente o objeto social, ou melhor, explica os aspectos que se apresentam do objeto social, no caso, a loucura (simbolizada como uma esfera de menor porte).

No entanto, o surgimento da ciência veio a abalar essa harmonia existente entre as teorias culturais e a loucura, criando uma contradição entre os dois sistemas representacionais. As representações culturais, percebidas como de estatuto inferior devido à emergência de paradigmas favoráveis à superioridade do conhecimento científico, perdem espaço para as representações derivadas da ciência. A atribuição de um estatuto superior a um dado sistema representacional (aqui, o sistema científico) está ligada a uma maior valoração social desse sistema. Por outro lado, a ciência não possui explicações com poder suficiente para dar con-

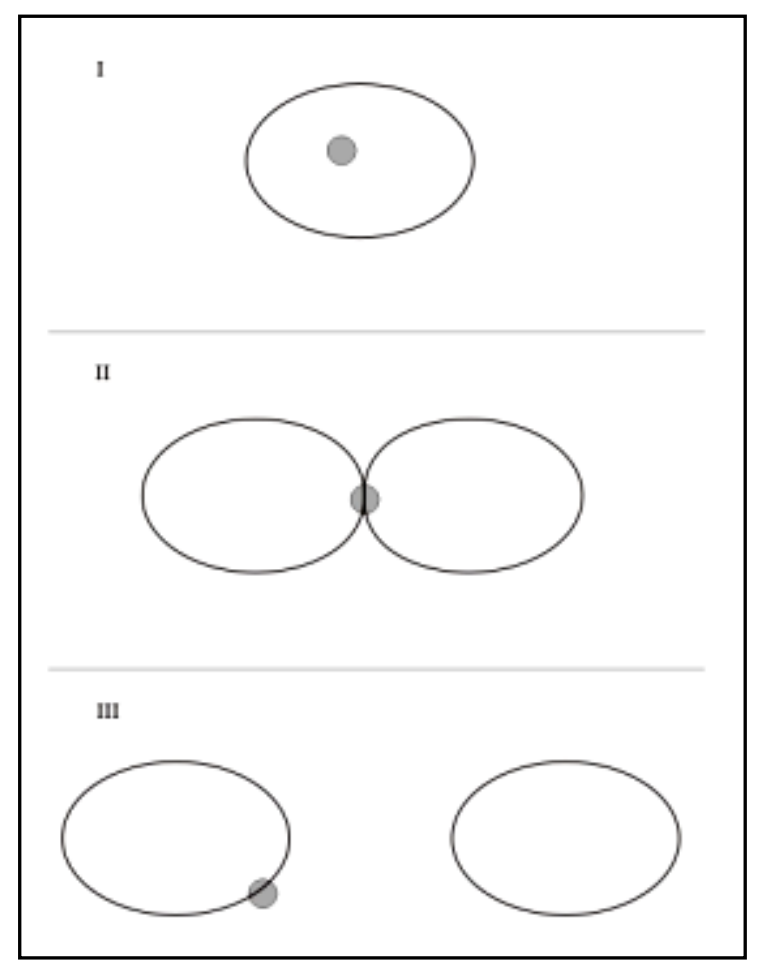

Figura 1. Representações gráficas das relações entre sistemas representacionais e objetos sociais. 
ta de todo o objeto social da loucura, e a relação do sistema representacional científico com o objeto social é apenas parcial. As representações do sistema cultural encarregam-se de lidar com os aspectos do objeto que não são esclarecidos pelas representações científicas. Pode-se dizer que dois sistemas cobrem o mesmo objeto.

Dessa forma, verifica-se uma cobertura complementar da loucura pelos dois sistemas, como representado na parte II da Figura 1. É essa situação que caracteriza o estudo de Wagner e colaboradores (1999b) com os moradores de Patna: existe aí uma representação mista, com raízes em ambos os sistemas, mas que parece indicar um afastamento do sistema cultural e movimento rumo à supremacia do sistema científico em relação à cobertura do objeto.

À medida que as representações vinculadas ao sistema cultural afastam-se do objeto social e que o sistema representacional científico ganha em importância e adesão por parte dos grupos, observa-se o curioso fenômeno que caracteriza atualmente a representação social da loucura. As representações científicas conseguem explicar apenas alguns aspectos da loucura, enquanto outras facetas da doença mental ainda não são passíveis de teorização com bases empíricas sólidas. Observa-se então uma espécie de vácuo representacional, uma falha dos processos geradores e modificadores das representações sociais. É possível identificar, na relação das representações com o objeto social uma deficiência estrutural: eis uma possível causa do problema apontado por Morant e Rose (2002), relacionado à ausência de âncoras para a loucura. É o que está representado na parte III da Figura 1.

Essa hipótese do vácuo representacional constitui uma tentativa de relacionar os fenômenos presentes na representação da loucura de forma que alguns pressupostos básicos da teoria das representações sociais sejam mantidos, ou seja, (1) as representações têm como função aproximar dos sujeitos aquilo que é novo e estranho, e (2) as representações sociais são dinâmicas, sendo passíveis de mudanças. O vácuo representacional está ligado ao que Gervais, Morant e Penn (1999) chamaram de ausência, no contexto da teoria e pesquisa em representações sociais. No entanto, essa ausência não parece estar diretamente ligada a nenhum dos tipos de ausência que os autores relacionaram em sua tipologia (teórica, metodológica, empírica e analítica/ interpretativa); trata-se, em uma primeira impressão, de uma ausência no plano da própria estrutura da representação, a que nos referimos como ausência de cobertura total entre representação e objeto.

Em conclusão, cabe tecer alguns comentários sobre a hipótese levantada acerca do fenômeno que chamamos vácuo representacional, de modo a situar o seu alcance e sua contribuição para a teoria das representações sociais. Em primeiro lugar, é importante esclarecer que nossa proposta foi meramente a de sugerir uma interpretação possível para organizar achados de estudos sobre a representação social da loucura. As características do vácuo representacional consistem num empreendimento incipiente do ponto de vista te- órico, tendo em vista que se baseiam em resultados de estudos diversos que não tiveram como objetivo investigar esse aspecto em particular das representações sociais. Devido a essa insuficiência em termos de embasamento empírico, não poderíamos falar, por exemplo, em modelo teórico.

Em segundo lugar, é preciso também apontar que o desenvolvimento da hipótese trabalhada só possui sentido quando se leva em conta a representação social da loucura compartilhada por alguns grupos de características específicas, que apresentam problemas para estruturar o conhecimento de senso comum sobre esse objeto. É o caso dos estudos que mencionamos quando comentamos sobre a falha estrutural. Em outras palavras, para que se possa admitir a validade da hipótese do vácuo representacional, há necessidade de contextualizá-la em relações de grupo que representa e objeto que é representado com configurações muito particulares. No caso de algum grupo possuir uma representação sobre a loucura que permita ancorá-la a outras noções bem definidas e coerentes entre si, não seria possível identificar, a princípio, a ocorrência de problemas de estruturação da representação. Por fim, um terceiro comentário refere-se à lembrança de que a validade da hipótese do vácuo representacional condiciona-se à existência efetiva de um problema de estruturação da representação, em oposição à possibilidade de que 0 aspecto não-familiar da representação social da loucura seja restrito apenas ao conteúdo representacional.

Nosso objetivo, de modo geral, foi atentar para uma particularidade existente na estruturação de algumas representações sociais. A melhor maneira de verificar a pertinência da hipótese levantada é a realização de pesquisas empíricas planejadas para pôr à prova as relações sugeridas. Segundo essa perspectiva, torna-se relevante tanto conduzir estudos adicionais sobre a representação social da loucura, especialmente projetados para abordar uma possível falha estrutural, utilizando delineamentos descritivos ou experimentais; como também buscar identificar outros objetos de representações que possam suscitar fenômenos semelhantes ao vácuo.

\section{Referências}

Abuchaem, J. (1981). Síntoma y angustia: estúdio psicanalítico. Buenos Aires: Belgrano.

Crawford, R. (1994). The boundaries of the self and the unhealthy other: reflections on health, culture and AIDS. Social Science and Medicine, 38(10), 13471365.

Farr, R. (2002). As raízes da psicologia social moderna. Petrópolis: Vozes.

Ferreira, A. B. de H. (1975). Novo dicionário da língua portuguesa. Rio de Janeiro: Nova Fronteira.

Festinger, L. (1957). A theory of cognitive dissonance. Stanford: Stanford University Press.

Foster, J. (2001). Unification and differentiation: a study of the social representation of mental illness. Papers on Social Representations, 10(3), 1-18.

Gervais, M. C., Morant, N., \& Penn, G. (1999). Making sense of “absence”: towards a typology of absence in social representations theory and research. Journal of the Theory of Social Behaviour, 29(4), 421-444.

Jodelet, D. (1989). Folies et réprésentations sociales. Paris: Presses Universitaries de France. 
Jodelet, D. (2001). Representações sociais: um domínio em expansão. In D Jodelet (Org.), As representações sociais (pp. 17-44). Rio de Janeiro: Editora da UERJ.

Jodelet, D. (2005). Loucuras e representações sociais. Petrópolis: Vozes.

Krause, M. (2002). Social representations of psychological problems: contents and transformations. Social Science Information, 41, 603-623.

Laraia, R. de B. (1997). Cultura: um conceito antropológico. Rio de Janeiro: Zahar.

Morant, N. (1995). What is mental illness? Social representation of mental illness among British and French mental health professionals. Papers on Social Psychology, 4, 41-55.

Morant, N., \& Rose, D. (2002). Loucura, multiplicidade e alteridade. In A. Arruda (Org.), Representando a alteridade (pp. 129-148). Petrópolis: Vozes.

Moscovici, S. (1978). A representação social da psicanálise. Rio de Janeiro: Zahar.

Moscovici, S. (1981). On social representations. In J. P. Forgas (Org.), Social cognition (pp. 181-209). Londres: Academic.

Moscovici, S. (1985). Introducción: el campo de la psicología social. In S. Moscovici (Org.), Psicología Social (vol. 1, pp. 17-37). Barcelona: Paidós.

Moscovici, S. (1987). Answers and questions. Journal for the Theory of Social Behaviour, 17, 513-529.
Moscovici, S. (2003). O fenômeno das representações sociais. In S. Moscovici (Org.), Representações sociais: investigações em psicologia social (pp. 29109). Petrópolis: Vozes.

Moscovici, S., \& Marková, I. (2003). Idéias e seu desenvolvimento: um diálogo entre Serge Moscovici e Ivana Marková. In S. Moscovici (Org.), Representações sociais: investigações em psicologia social (pp. 305-387). Petrópolis: Vozes.

Nascimento-Schulze, C. M., \& Camargo, B. V. (2000). Psicologia social, representações sociais e métodos. Temas em Psicologia, 8(3), 287-299.

Sperber, D. (2001). O estudo antropológico das representações: problemas e perspectivas. In D. Jodelet (Org.), As representações sociais (pp. 91-103). Rio de Janeiro: Editora da UERJ.

Wagner, W. (1998). Sócio-gênese e características das representações sociais. In A. S. P. Moreira \& D. C. Oliveira (Orgs.), Estudos interdisciplinares de representação social (pp. 3-25). Goiânia: AB.

Wagner, W., Duveen, G., Farr, R., Jovchelovitch, S., Lorenzi-Cioldi, F., Marková, I., \& Rose, D. (1999a). Theory and method of social representations. Asian Journal of Social Psychology, 2, 95-125.

Wagner, W., Duveen, G., Themel, M., \& Verma, J. (1999b). The modernization of tradition: thinking about madness in Patna, India. Culture and Psychology, 5(4), 413-445.

João Fernando Rech Wachelke é mestrando no Programa de Pós-Graduação em Psicologia da Universidade Federal de Santa Catarina. Endereço para correspondência: Rua Octavio Lebarbenchon, 69; Florianópolis, SC; CEP 88037-290. Tel.: (48) 3233-3785. E-mail: wachelke@yahoo.com 